\title{
Nano-Mechanical and Piezoelectric Properties on PZT Thin Films
}

\author{
D. E. Olivas-Ortega ${ }^{1,3}$, J. Ramos-Cano ${ }^{2}$, R. P. Talamantes-Soto ${ }^{1}$, C. López-Meléndez ${ }^{3}$ and A. Hurtado- \\ Macias $^{1}$ \\ 1. Centro de Investigación en Materiales Avanzados S.C., and Laboratorio Nacional de Nanotecnología, \\ Miguel de Cervantes 120, Complejo Industrial Chihuahua, Chihuahua, C.P. 31109 México. \\ 2. Universidad autónoma de Coahuila (UADEC), Facultad de metalurgia, carretera 57 kilómetro 4.5 C.P. \\ 25725, Monclova Coahuila, México. \\ 3. Universidad La Salle Chihuahua, Prol. Lomas de Majalca No. 11201, CP 31020, Chihuahua, México.
}

The applications of ferroelectric thin films can be used in the field of electronics devises such as sensors, capacitors, MEMS and energy harvesting power sources. It does require an outstanding performance of ferroelectric response, meaning thin films lead-based ferroelectric $\mathrm{Pb}\left(\mathrm{Z}_{\mathrm{x}} \mathrm{T}_{1-\mathrm{x}}\right) \mathrm{O}_{3}, \mathrm{PbTiO}_{3}$, can act as potential candidates for that [1-4]. In that regard, lead zirconate titanate (PZT) thin films with composition located near of the morphotropic phase boundary is one of the most attractive candidates for this kinds of applications, because possess suitable and straightforward ferroelectric properties [3].

In this work includes structural characterization which were used a grazing incidence X-ray diffraction (GIXRD), scanning electron microscopy (SEM) and high resolution transmission electron microscopy (HRTEM) techniques. This with the finality to understand the phase and structure parameters. Ferroelectric $\mathrm{Pb}\left(\mathrm{Zr}_{0.52} \mathrm{Ti}_{0.48}\right) \mathrm{O}_{3}$ thin films were deposited by Chemical Vapor Deposition Assisted by Aerosol (CVD-AA) method on $\mathrm{Pt}\left(\begin{array}{lll}1 & 1 & 1\end{array}\right) / \mathrm{TiO}_{2} / \mathrm{SiO}_{2} / \mathrm{Si}\left(\begin{array}{lll}1 & 0 & 0\end{array}\right)$ commercial substrate at $350^{\circ} \mathrm{C}$, followed by annealing processing at $650^{\circ} \mathrm{C}$ for one hour. On the other hand, mechanical behavior was analyzed of $\mathrm{Pb}\left(\mathrm{Zr}_{0.52} \mathrm{Ti}_{0.48}\right)_{3}$ thin films using Continuous Stiffness Measurement (CSM) technique in Nanoindentation, which enables a continuous measurement during loading, and not just at the point of initial unloading [5].

The hardness and elastic modules values were $\mathrm{H}=7 \pm 0.16 \mathrm{GPa}$ and $\mathrm{E}=130 \pm 2.7 \mathrm{GPa}$ respectively. These values were taken in the range $0-100 \mathrm{~nm}$ of the displacement into the surface, to avoid the influence of the substrate due to films thickness is $190 \pm 10 \mathrm{~nm}$. H and $\mathrm{E}$ in this range are consistent due to good homogeneity of the $\mathrm{Pb}\left(\mathrm{Zr}_{0.52} \mathrm{Ti}_{0.48}\right) \mathrm{O}_{3}$ material. Finally, the optimums $\mathrm{Pb}\left(\mathrm{Zr}_{0.52} \mathrm{Ti}_{0.48}\right) \mathrm{O}_{3}$ film was subjected to study the ferroelectric and piezoelectric properties by the Piezoresponse Force Microscopy (PFM) technical in Atomic Force Microscope (AFM). Furthermore, MFP3D lithography was used to determinate good polarization-switching mechanism of the domains in the optimums ferroelectric $\mathrm{Pb}\left(\mathrm{Zr}_{0.52} \mathrm{Ti}_{0.48}\right) \mathrm{O}_{3}$ films.

\section{References:}

[1] D G Wang, C Z Chen, J Ma, T H Liu, Appl. Surf. Sci. 255 (2008)1637-1645.

[2] Z Xu, W Chan, Acta Mater. 55 (2007) 3923-3928.

[3] M Lisca, L Pintilie, M Alexe, C M Teodorescu, Appl. Surf. Sci. 252 (2006) 4549-4552.

[4] K Uchino, Ferroelectric Devices, Marcel Dekker. Inc., New York, 2000.

[5] X Li, B Bhushan, Mater. Charact. 48 (2002) 11-36. 

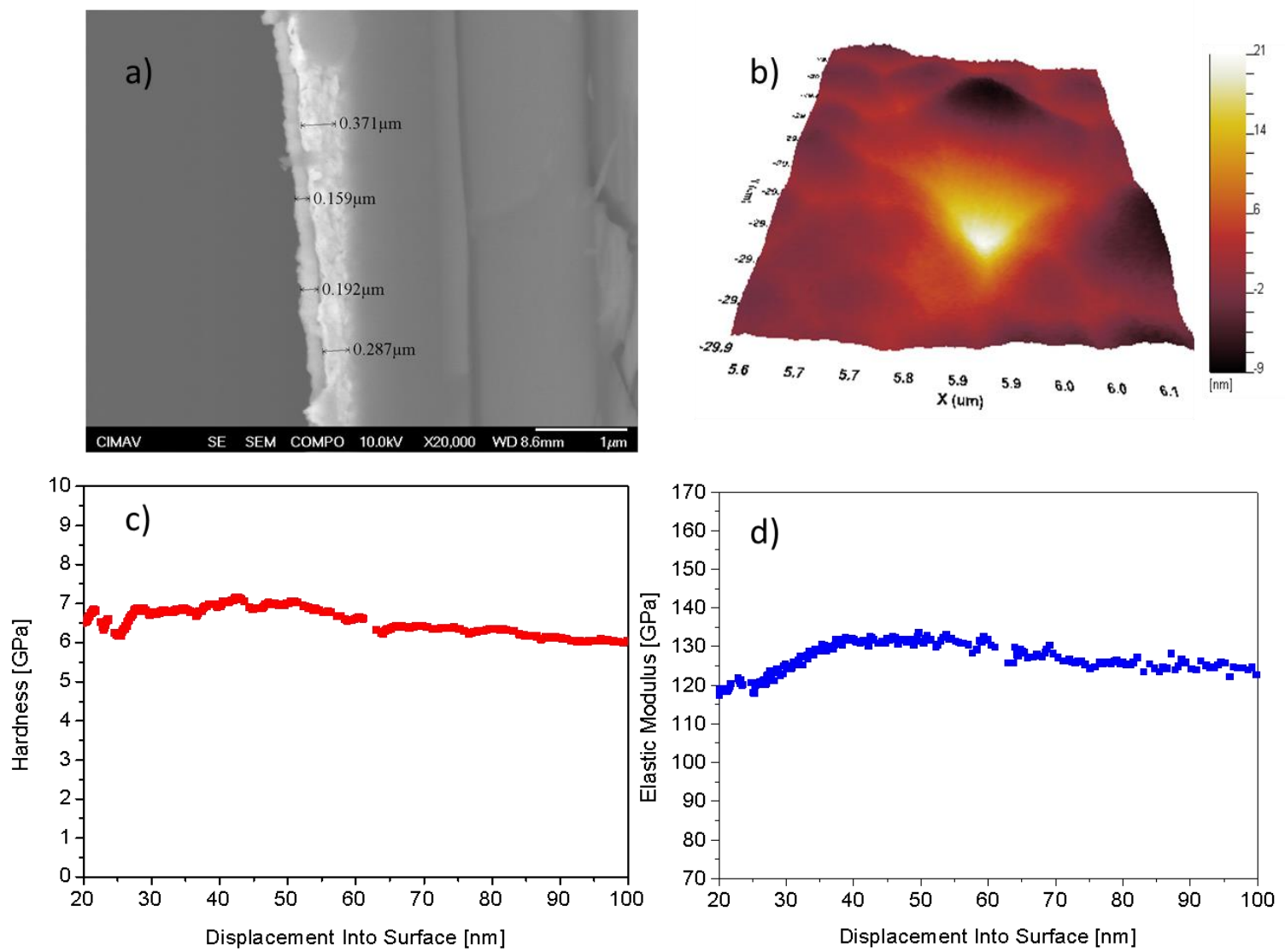

Figure 1. a) Thickness of the PZT thin films by SEM, b) AFM imagen of residual indentation Berkovich Tip, Hardness and Elastic modulus behavior versus displacement into surface c) and d) respectively.
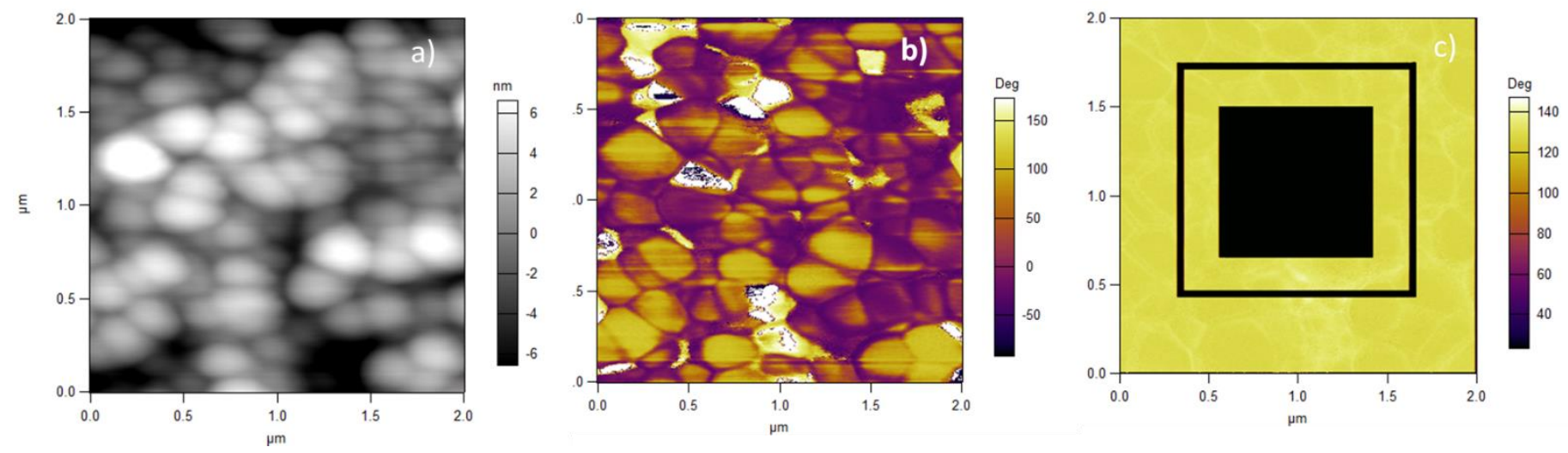

Figure 2. a) Topography AFM Imagen in contact mode scan, b) Piezoelectric force microscopy mode, and c) Nano-lithography imagen by PFM. 